\title{
Commentary: GGOogle maps for the adult lung
}

\author{
Joanna Sesti, MD, and Subroto Paul, MD, MPH
}

From Thoracic Surgical Services, RWJBarnabas Health, West Orange, NJ.

Disclosures: Authors have nothing to disclose with regard to commercial support.

Received for publication Aug 29, 2019; revisions received Aug 29, 2019; accepted for publication Aug 29, 2019; available ahead of print Oct 11, 2019.

Address for reprints: Joanna Sesti, MD, RWJBarnabas Health, 101 Old Short Hills Rd, Ste. 302, West Orange, NJ 07052 (E-mail: Joanna.Sestil@rwjbh.org).

J Thorac Cardiovasc Surg 2020;159:1580

0022-5223/\$36.00

Copyright $(\subset) 2019$ by The American Association for Thoracic Surgery

https://doi.org/10.1016/j.jtcvs.2019.08.107

Life before Google Maps was hard! Going in circles, asking strangers for directions, reading maps upside down, stopping at gas stations, and suffering through hours in a car was stressful, irritating, and now thankfully due to GPSenabled apps, like Google Maps, a thing of the past. In this issue of the Journal, Park and colleagues ${ }^{1}$ try to define the best "map" to find ground-glass opacities (GGOs) in the operating room.

In the current era of low-dose computed tomography (CT) screening, GGOs and small nodules $(<7 \mathrm{~mm})$ have become a common reason for thoracic surgical evaluation. Current indications for the resection of GGOs are increasing size and/or a solid component of at least $5 \mathrm{~mm}$. GGOs are difficult to palpate due to their small size and substance, being similar to the surrounding lung parenchyma. Finding a GGO in the operating room without guidance can be fraught with frustration, especially in the era of minimally invasive surgery where palpation is limited (video-assisted thoracoscopic surgery [VATS]) or eliminated (robotics). Many techniques have been developed to locate GGOs preoperatively, including CT-guided wire localization or injection of dyes, radiotracers, and coils, navigational bronchoscopic equivalents, or intraoperative ultrasound and other imaging techniques. Clearly, there is more than one way to crack an egg. With limited prospective data comparing the various techniques, the most efficient technique leaving the least amount of mess is not known.

Park and colleagues present the results of a comparative prospective trial comparing chest CT-guided hook wire versus lipiodol injection localization for the identification

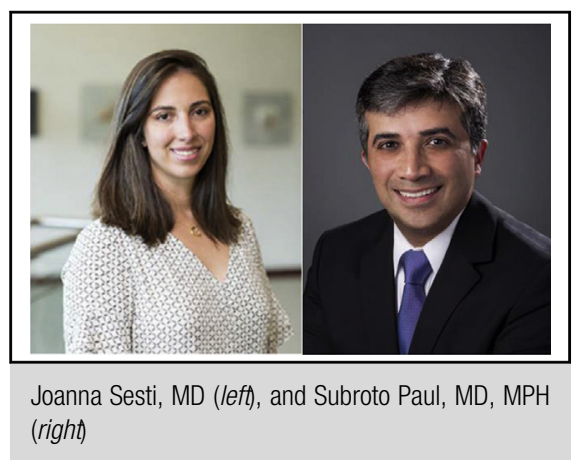

\section{Central Message \\ Lipiodol localization is as effective as hook- wire localization for GGOs during VATS but with less complications.}

See Article page 1571. of GGOs during VATS. ${ }^{1}$ The authors find no difference in success rates for localization (primary endpoint) but greater rates of hemorrhage, dislodgement, and initial positive margins in the hook wire cohort. The study is limited by its nonrandomized nature, with 8 study sites each performing only 1 technique. Also, as VATS was the only surgical approach used along with fluoroscopy to initially mark the area of interest on the lung, are the results applicable to roboticassisted methods?

Despite its limitations, this study is among the first to prospectively compare localization techniques. With more than one technique available, none is clearly perfect, or we would all use it. Each of these various localization modalities are tools, with each tool being best suited for a particular application. The study provides valuable data that along with future studies may make the pain and frustration of finding a GGO in the operating room a thing of the past.

\section{Reference}

1. Park CH, Lee SM, Lee JW, Hwang SH, Kwon W, Han K, et al. Hook-wire localization versus lipiodol localization for patients with pulmonary lesions having ground-glass opacity. J Thorac Cardiovasc Surg. 2020;159:1571-9.e2. 